\title{
First-in-man intravenous implantation of stromal vascular fraction in psoriasis: a case study
}

This article was published in the following Dove Press journal: International Medical Case Reports Journal

\author{
Kristin Comella' \\ Michelle Parlo \\ Rosemary Daly ${ }^{2}$ \\ Kellie Dominessy ${ }^{2}$ \\ 'US Stem Cell, Inc., Sunrise, FL, USA; \\ ${ }^{2}$ US Stem Cell Clinic, Sunrise, FL, USA
}

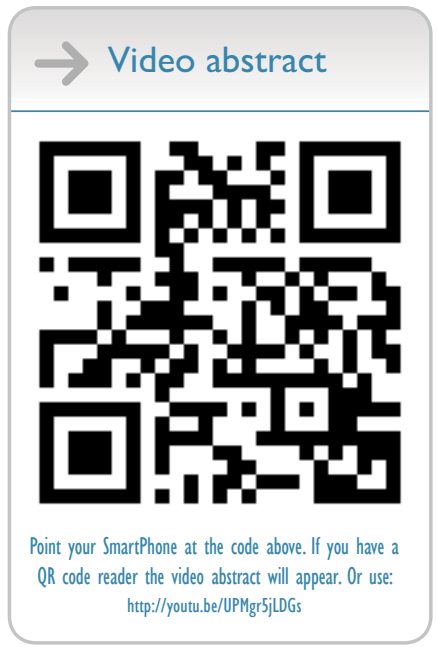

Correspondence: Kristin Comella US Stem Cell, Inc., I3794 NW 4th Street, Suite 212 , Sunrise, FL 33325, USA

$\mathrm{Tel}+\mathrm{I} 954835$ I500

Email kcomella@us-stemcell.com
Background: Stromal vascular fraction (SVF) is a mixture of adipose-derived stem cells/ mesenchymal stem cells, endothelial/progenitors, pericytes, fibroblasts, and other cells obtained from fat tissue. A small sample of fat or adipose tissue can be obtained under local anesthesia using a cannula. After an enzymatic digestion and centrifugation, the adipocytes (fat cells) are removed to obtain an SVF. Here, we describe the rationale and, to our knowledge, the first clinical implementation of SVF intravenously in a patient with severe psoriasis.

Methods: Adipose tissue $(60 \mathrm{~mL})$ was collected under local anesthesia via a mini-lipoaspirate procedure. The SVF was separated from the adipocytes via centrifugation after an enzymatic digestion. The cells were resuspended in normal saline and injected via bolus push intravenous. The subject was monitored over a period of 12 months for safety (adverse events), medication changes, and quality of life parameters.

Results: The patient did not report any safety concerns and did not experience any severe adverse events. The patient demonstrated a significant decrease in symptoms with a noticeable difference in skin quality appearance. Psoriasis area and severity index score went from 50.4 at baseline to 0.3 at 1 month follow-up.

Conclusion: Overall, the patient reported improved quality of life and willingness to continue treatments. This successful initial case study demonstrates that this may be a feasible treatment plan for patients suffering from psoriasis.

Keywords: adipose tissue, adipose-derived stromal/stem cells, autoimmune disease, cell therapy, mesenchymal stem cells, psoriasis, stem cells, stromal vascular fraction

\section{Background}

Psoriasis is an autoimmune disease affecting about $2 \%$ of the population worldwide and approximately 7.5 million people in the United States. ${ }^{1}$ Psoriasis patients present with erythematous scaly well-defined plaques, with the scalp, knees, elbows, hands, and feet being the most commonly affected areas. ${ }^{2}$ Approximately $20 \%$ of psoriasis patients present with moderate to severe psoriasis with more than $5 \%$ of the body surface affected. Fifteen percent of patients with psoriasis will develop psoriatic arthritis, occasionally with joint complaints such as dactylitis, sacroiliitis, enthesopathy, and spondylitis, occurring before cutaneous psoriasis. This condition can cause joint destruction due to the chronic inflammation. There are also significant comorbidities associated with psoriasis. ${ }^{3}$ There is a $58 \%$ risk of cardiovascular disease and $43 \%$ increased risk of stroke. The risk of diabetes is $30 \%$ higher in patients with severe psoriasis. Other conditions such as osteoporosis, uveitis, depression, and liver disease are 
also linked to psoriasis. All of these conditions lessen when psoriasis and the associated inflammation are addressed.

Multipotential adult stem cells or MSCs are currently being studied in a variety of diseases and injuries. MSCs can be found in many tissues throughout the body and are thought to play a very critical role in the healing cascade. When MSCs are placed into culture or in vitro, they demonstrate an ability to differentiate down several different tissue pathways. MSCs are part of the body's natural healing mechanism and as such represent a potential therapy in a variety of diseases. ${ }^{4,5}$ The cells are thought to have immunomodulatory properties and can stimulate a healing response by reducing inflammation. For this reason, MSCs may be beneficial for patients experiencing excessive inflammation, as is present in autoimmune diseases like psoriasis. Stem cells may reduce the inflammatory response in psoriasis by affecting the epidermis and regulating T cells. ${ }^{6}$

According to the literature, MSCs have properties of angiogenesis and mitogenesis, leading to increased blood supply in areas of ischemic tissue. ${ }^{7}$ The MSCs promote healing by creating a paracrine effect leading to a reduction in inflammation, apoptosis in cells, and fibrotic tissue. ${ }^{8}$ Cells can secrete biological factors to communicate, which in turn regulates the tissue regeneration in the body. Pericytes are attached to the small vasculature throughout the body and are believed to be the precursor to the MSC. The pericyte is called upon after injury and converted via cell-to-cell communication into a medicinal cell. At this point, an immunomodulatory cascade of cytokines, molecules, and other proteins occurs to create a trophic environment leading to the healing of injury or tissue regeneration. For patients with autoimmune diseases, the body is in a chronic state of inflammation, and with MSC therapy, the proinflammatory cytokines such as IL-6, IL-17, and TNF- $\alpha$ may be inhibited. ${ }^{9}$ According to Lee et al, ${ }^{9}$ MSCs can reduce skin inflammation after systemic infusion into mice exposed to psoriasis-like skin inflammation. In addition to the reduction of the proinflammatory cytokines, chemokines such as CCL17, CCL20, and CCL27 were reduced in the mice skin.

One of the most plentiful sources of MSCs in the human body is adipose or fat tissue. ${ }^{10}$ Fat can be easily isolated via mini-lipoaspiration in an outpatient facility using local anesthesia only. The MSCs that are present in the fat are called adipose-derived stem cells (ADSCs) and can differentiate into fat, bone, cartilage, and muscle in vitro. ADSCs contribute to the paracrine effect with the expression of many different cytokines and growth factors to promote tissue repair and reduce inflammation. In addition, ADSCs promote angiogen- esis or the formation of new blood vessels in combination with the regulation of the local inflammation process. ${ }^{11,12}$

The stromal vascular fraction (SVF) is a mixture of cells including the MSCs with the adipocyte or fat cell population depleted or removed. It can be separated at the bedside of the patient in approximately 30-90 minutes and prepared for immediate injection. SVF expresses a wide range of cytokines and growth factors that are known to be part of the healing cascade. SVF contains a high percentage of cells that express the protein CD34, which is known to be present on hematopoietic stem cells, MSCs, and pericytes..$^{13}$ This cluster of differentiation is part of the periendothelial network and is thought to be integral to the angiogenesis process. The use of SVF has been reported in a variety of indications including osteoarthritis, ${ }^{14-16}$ degenerative disc disease, ${ }^{17}$ sclerosis, ${ }^{18}$ tendinopathy, ${ }^{19}$ congestive heart failure, ${ }^{20}$ chronic obstructive pulmonary disease, ${ }^{21}$ radiation necrosis, ${ }^{22}$ xerostomia, ${ }^{23}$ and multiple sclerosis. ${ }^{24}$ In addition, two studies have been published demonstrating the safety of SVF for a variety of indications used in a clinical outpatient setting. ${ }^{25,26}$ With a large number of MSCs and a low number of white blood cells, adipose tissue is a more ideal source for in-clinic cellular medicine as compared to bone marrow. ${ }^{27}$ Adipose tissue also contains a large number of pericytes which are the precursor to MSCs with regenerative or healing properties. ${ }^{28,29}$ Because fat collection is a well-established method, the SVF collection of cells and reintroduction into damaged tissue may represent a safe novel therapeutic approach. We report the first-in-man intravenous (IV) injection of SVF in a patient with psoriasis.

\section{Methods \\ Study design}

This first-in-man case study was completed on a 43 year old male with severe psoriasis. Written informed consent regarding the experimental nature of the protocol and publication of outcome and data was obtained from the patient. SVF was suspended in approximately $3 \mathrm{~mL}$ of normal saline prior to bolus IV injection through a 23 gauge butterfly needle. The patient was monitored for serious adverse events (SAEs) to include any fatal or life-threatening event that led to hospitalizations, or required major medical intervention, as well as adverse events. Weight, blood pressure, height, and pulse were collected as the physical parameters. The patient was evaluated for skin quality via the psoriasis area and severity index score, as well as quality of life parameters. Baseline blood work is shown in Table 1. The complete blood count was unremarkable, and repeat testing was not required. At 
Table I Baseline complete blood count

\begin{tabular}{llll}
\hline Test name & Result & Ref range & Units \\
\hline WBC & 9.1 & $3.5-10.1$ & $\mathrm{bi} / \mathrm{L}$ \\
RBC & 4.8 & $4.31-5.48$ & $\mathrm{tri} / \mathrm{L}$ \\
Hemoglobin & 15.0 & $13.5-17.0$ & $\mathrm{~g} / \mathrm{dL}$ \\
Hematocrit & 45.8 & $40.1-50.1$ & $\%$ \\
MCV & 95 & $80-100$ & $\mathrm{fL}$ \\
MCH & 31 & $28-33$ & $\mathrm{pg}$ \\
MCHC & 33 & $32-35$ & $\mathrm{~g} / \mathrm{dL}$ \\
RDW SD & 43 & $37-47$ & $\mathrm{fL}$ \\
RDW CV & 12 & $12-15$ & $\%$ \\
Platelet & 183 & $150-400$ & $\mathrm{bi} / \mathrm{L}$ \\
\hline
\end{tabular}

Abbreviations: RDW-CV, red cell distribution width coefficient of variation RDW SD, red cell distribution width standard deviation; $\mathrm{MCH}$, mean corpuscular hemoglobin; MCHC, mean corpuscular hemoglobin concentration; MCV, mean corpuscular volume; RBC, red blood cell; RDW, red cell distribution width; WBC, white blood cell.

the time of baseline treatment, the patient was not taking any prescription medications as all had previously failed to provide clinical improvements. Previous medications included biologics, topicals, immunosuppressants, steroids, and light therapy. The patient did not start any new medication or therapies during the follow-up period.

\section{Cell preparation and study intervention}

Using a scalpel blade \#11, a small incision was made after local anesthesia. A standard tumescent solution containing $500 \mathrm{~mL}$ normal saline, $25 \mathrm{~mL}$ of lidocaine $(2 \%), 4 \mathrm{~mL}$ of sodium bicarbonate $(8.4 \%)$, and $0.5 \mathrm{~mL}$ of epinephrine
$(1 \mathrm{mg} / \mathrm{mL})$ was administered into the subcutaneous space using an infiltration cannula. A Toomey syringe and a 3 mm Mercedes cannula was used to collect approximately $60 \mathrm{~mL}$ of fat tissue after infranate depletion. The SVF was isolated using a commercially available collection kit and enzyme (Adipocell ${ }^{\mathrm{TM}}$ Enzyme, US Stem Cell, Inc. Sunrise, FL, USA). The final SVF pellet was resuspended in $3 \mathrm{~mL}$ of normal saline for administration to the patient approximately 45 minutes later.

\section{Results}

\section{Adipose and SVF collection}

No safety incidences were reported during the mini-lipoaspirate procedure or the IV injection. After isolating the SVF and removing the adipocyte population, approximately 30-60 million nucleated cells remain. As reported in previous publications, the SVF population typically expresses greater than $50 \% \mathrm{CD} 34$, with high viability ( $>90 \%$ ). The cells also demonstrate the ability to differentiate down various pathways such as adipogenesis, osteogenesis, and chondrogenesis. ${ }^{14}$

\section{Efficacy outcomes}

The patient reported a decrease in symptoms and improvement in quality of life over the 12-month follow-up period. Figure 1 shows an image at baseline and at 3 months post IV delivery of SVF. The numerous psoriasis plaques present on

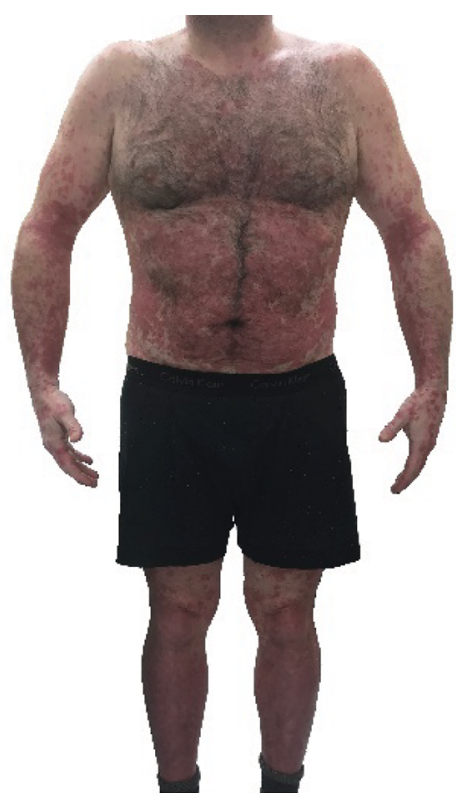

B

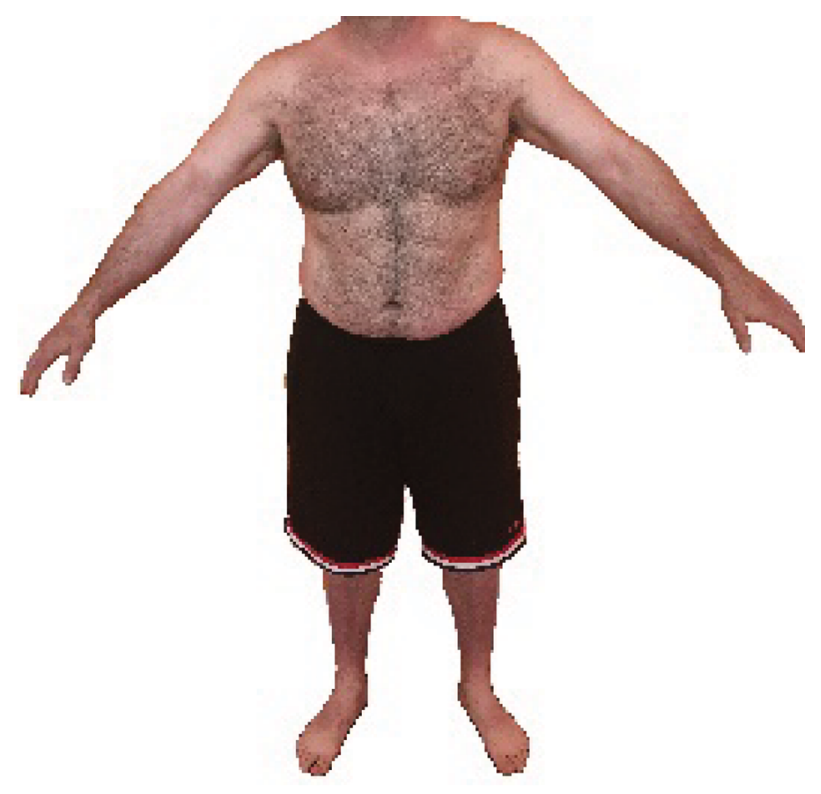

Figure I Picture of patient's skin at baseline (A) and 3 months after IV delivery of SVF (B).

Notes: Clear resolution of inflammed red skin at 3 months which was maintained during the 12-month follow-up period.

Abbreviations: IV, intravenous; SVF, stromal vascular fraction. 
initial review were completely resolved 1 month post single IV injection and continued to be resolved at 12 month follow up. Psoriasis area and severity index score scores were 50.4 at baseline and 0.3 at 1 month. At the time of treatment, the patient was no longer using any medications as his symptoms had failed to improve over two decades. The patient did not start any additional therapies or medications during the follow-up period.

\section{Safety analysis}

No SAEs were reported throughout the monitoring. The patient did not report any other events and was able to resume normal activities within days after the procedure.

\section{Discussion}

Autoimmune diseases such as psoriasis are a result of overactive T cells, and current clinical options for therapy are limited. Promising preclinical results and a few clinical studies using cellular medicine have been reported in the literature. Outpatient in-clinic protocols using SVF may be a feasible therapy for these debilitating conditions. Additional studies with larger sample sizes could determine appropriate dosing (ie, number of cells) and the need for repeat therapy.

As stem cell therapy is a novel approach and the full mechanisms of action are not fully understood, it is unclear to what extent this therapy may facilitate tissue repair or reverse the effects of autoimmune diseases. Clinical benefits may be as a result of stem cell engraftment or due to a paracrine/ immunomodulatory effect. However, patient improvements are most likely due to a complex cascade of events regulated by a mixture of growth factors and cytokines associated with the SVF population. This complex interaction may reduce inflammation and stimulate the formation of new, healthy tissue.

Patients with autoimmune diseases, and more specifically psoriasis, frequently experience comorbidities. ${ }^{30-32}$ Psoriasis also increases the risk of depression and suicide. ${ }^{33}$ Current treatment protocols include topical treatments which may only relieve symptoms temporarily. Systemic treatments (taken orally, or by injection or infusion) include acitretin, cyclosporine, and methotrexate. ${ }^{34}$ The unique immunomodulatory properties of the MSCs make them a promising tool for this inflammatory disease. Psoriasis is an inflammatory response as a result of a complex interaction among the epidermis, dermis, immune system, blood vessels, metabolic system, neuroendocrine system, and hematopoietic system. ${ }^{35}$ Injected cells may work to either prevent further damage to tissue or repair the damage created. ${ }^{36}$ Stem cells may provide an attractive approach to tissue regeneration for autoimmune conditions by promoting healing, reducing inflammation, and resetting the immune system via an immunomodulatory cascade of events. ${ }^{37}$

\section{Conclusion}

This first-in-man case demonstrated the safety and feasibility of IV injection of SVF in a severe psoriasis patient. There were no major safety events, and the protocol was well tolerated. In addition, the patient demonstrated a significant decrease in psoriasis symptoms with noticeable improvement in skin quality. Because this case study suggested that SVF is safe and feasible, future studies are warranted to determine the long-term effects. Large clinical studies could establish the expected outcomes and efficacy of the therapy. Doubleblind studies could address any theoretical safety concerns and to what extent the cells improve an overactive immune system.

\section{Declarations \\ Ethics approval and consent to participate}

The patient consented and agreed to participate in the study.

\section{Consent for publication}

The patient consented and agreed to have their data published.

\section{Availability of data and materials}

The datasets used during and/or analyzed during the current study are available from the corresponding author on reasonable request.

\section{Acknowledgment}

This study was partially funded by US Stem Cell, Inc.

\section{Author contributions}

$\mathrm{KC}$ designed the protocol. MP, KD, and RD were responsible for clinical procedures and follow-up of patients. $\mathrm{KC}$ analyzed the data and wrote the manuscript. All authors contributed toward data analysis, drafting and critically revising the paper and agree to be accountable for all aspects of the work. All authors read and approved the final manuscript.

\section{Disclosure}

$\mathrm{KC}$ is an officer of US Stem Cell, Inc. US Stem Cell is a publicly trading company providing physician-based stem cell therapies to human and animal patients as well as a 
developer of autologous cell therapies. The authors report no other conflicts of interest in this work.

\section{References}

1. Menter A, Gottlieb A, Feldman SR, et al. Guidelines of care for the management of psoriasis and psoriatic arthritis: Section 1. Overview of psoriasis and guidelines of care for the treatment of psoriasis with biologics. J Am Acad Dermatol. 2008;58(5):826-850.

2. Helmick CG, Lee-Han H, Hirsch SC, Baird TL, Bartlett CL. Prevalence of psoriasis among adults in the U.S: 2003-2006 and 2009-2010 national health and nutrition examination surveys. Am J Prevent Med. 2014;47(1):37-45.

3. Rachakonda TD, Schupp CW, Armstrong AW. Psoriasis prevalence among adults in the United States. $J$ Am Acad Dermatol. 2014;70(3):512-516.

4. Hematti P, Keating A. Mesenchymal stromal cells in regenerative medicine: a perspective. Mesenchymal Stromal Cells. 2012:3-16.

5. Przybyt E, Harmsen MC. Mesenchymal stem cells: promising for myocardial regeneration? Curr Stem Cell Res Ther. 2013;8(4):270-277.

6. Owczarczyk-Saczonek A, Krajewska-Włodarczyk M, Kruszewska A, Placek W, Maksymowicz W, Wojtkiewicz J. Stem cells as potential candidates for psoriasis cell-replacement therapy. Int J Mol Sci. 2017;18(10)

7. Bronckaers A, Hilkens P, Martens W, et al. Mesenchymal stem/stromal cells as a pharmacological and therapeutic approach to accelerate angiogenesis. Pharmacol Ther. 2014;143(2):181-196.

8. Caplan AI, Correa D. The MSC: an injury drugstore. Cell Stem Cell. 2011;9(1):11-15.

9. Lee YS, Sah SK, Lee JH, Seo KW, Kang KS, Kim TY. Human umbilical cord blood-derived mesenchymal stem cells ameliorate psoriasis-like skin inflammation in mice. Biochem Biophys Rep. 2016;9:281-288.

10. Minteer D, Marra KG, Rubin JP. Adipose-derived mesenchymal stem cells: biology and potential applications. Adv Biochem Eng Biotechnol. 2012:129:59-71.

11. Gimble JM, Katz AJ, Bunnell BA. Adipose-derived stem cells for regenerative medicine. Circ Res. 2007;100(9):1249-1260.

12. Rehman J, Traktuev D, Li J, et al. The secretion of angiogenic and anti-apoptotic factors by human adipose stromal cells. Circulation. 2004;109(10):1291-1298.

13. Traktuev DO, Merfeld-Clauss S, Li J, et al. A population of multipotent CD34-positive adipose stromal cells share pericyte and mesenchymal surface markers, reside in a periendothelial location, and stabilize endothelial networks. Circ Res. 2008;102(1):77-85.

14. Michalek J, Moster R, Lukac L, et al. WITHDRAWN: Autologous adipose tissue-derived stromal vascular fraction cells application in patients with osteoarthritis. Cell Transplant. Epub 2015 Jan 20.

15. Bansal H, Comella K, Leon J, et al. Intra-articular injection in the knee of adipose derived stromal cells (stromal vascular fraction) and platelet rich plasma for osteoarthritis. J Transl Med. 2017;15(1):141.

16. Siennicka K, Zolocinska A, Stepien K, et al. Adipose-derived cells (stromal vascular fraction) transplanted for orthopedical or neurological purposes: are they safe enough? Stem Cells Int. 2016;2016:5762916.

17. Comella K, Silbert R, Parlo M. Effects of the intradiscal implantation of stromal vascular fraction plus platelet rich plasma in patients with degenerative disc disease. J Transl Med. 2017;15:12.

18. Daumas A, Magalon J, Jouve E, et al. Granel. Long-term follow-up after autologous adipose-derived stromal vascular fraction injection into fingers in systemic sclerosis patients. Curr Res Transl Med. 2017;65(1):40-43.
19. Usuelli FG, Grassi M, Maccario C, Viganoâ M, Lanfranchi L, Montrasio US. Intratendinous adipose-derived Stromal Vascular Fraction (SVF) injection provides a safe, efficacious treatment for achilles tendinopathy: results of a randomized controlled clinical trial at a 6-month followup. Knee Surg Sports Traumatol Arthrosc. Epub 2017 Mar 1.

20. Comella K, Parcero J, Bansal H, et al. Effects of the intramyocardial implantation of stromal vascular fraction in patients with chronic ischemic cardiomyopathy. J Transl Med. 2016;14(1):158.

21. Comella K, Perez J, Ichim T, Lopez J, Limon J, Moreno RC. Autologous stromal vascular fraction in the intravenous treatment of end-stage chronic obstructive pulmonary disease: A Phase I trial of Safety and Tolerability. J Clin Med Res. 2017;9(8):701-708.

22. Parcero JJ, Perez JA, Patel AN, et al. Autologous adipose-derived stromal stem cell implantation to resolve critical limb ischemia: case report. Cureus. 2014;6(5):e182.

23. Comella K, Bell W. First in man intraglandular implantation of stromal vascular fraction and adipose derived stem cells plus platelet rich plasma in irradiation induced gland damage: A Case Study. Int Med Case Rep J. 2017;10:295-299.

24. Riordan N, Ichim T, Min W, Wang H, Solano F, Lara F. Non-expanded adipose stromal vascular fraction cell therapy for multiple sclerosis. $J$ Transl Med. 2009;7:29.

25. Comella K, Parlo M, Daly R, et al. Safety analysis of autologous stem cell therapy in a variety of degenerative diseases and injuries using the stromal vascular fraction. J Clin Med Res. 2017;9(11):935-942.

26. Lander EB, Berman MH, See JR. Safety of stromal vascular fraction cells applications in chronic pain. Tech Reg Anesth Pain Management. 2015;19(1-2):10-13.

27. Panfilov IA, de Jong R, Takashima S, Duckers HJ. Clinical study using adipose-derived mesenchymal-like stem cells in acute myocardial infarction and heart failure. Methods Mol Biol. 2013;1036: 207-212.

28. Jang Y, Koh YG, Choi YJ, et al. Characterization of adipose tissuederived stromal vascular fraction for clinical application to cartilage regeneration. In Vitro Cell Dev Biol Anim. 2015;51(2):142-150.

29. Aust L, Devlin B, Foster S, et al. Yield of human adipose-derived adult stem cells from liposuction aspirates. Cytotherapy. 2004;6(1):7-14.

30. Najarian DJ, Gottlieb AB. Connections between psoriasis and Crohn's disease. J Am Acad Dermatol. 2003;48:805-821.

31. Armstrong AW, Gelfand JM, Boehncke WH, et al. Cardiovascular comorbidities of psoriasis and psoriatic arthritis: a report from the GRAPPA 2012 annual meeting. J Rheumatol. 2013;40:1434-1437.

32. Griffiths CE, Barker JN. Pathogenesis and clinical features of psoriasis. Lancet. 2007;370:263-271.

33. Kurd SK, Troxel AB, Crits-Christoph P, Gelfand JM. The risk of depression, anxiety, and suicidality in patients with psoriasis: a populationbased cohort study. Arch Dermatol. 2010;146:891-895.

34. Menter A, Korman NJ, Elmets CA, et al. Guidelines of care for the management of psoriasis and psoriatic arthritis: section 4. Guidelines of care for the management and treatment of psoriasis with traditional systemic agents. J Am Acad Dermatol. 2009;61:451-485.

35. Hou R, Li J, Niu X, et al. Stem cells in psoriasis. J Dermatol Sci. 2017; 86(3):181-186.

36. Shin TH, Kim HS, Choi SW, Kang KS. Mesenchymal stem cell therapy for inflammatory skin diseases: clinical potential and mode of action. Int J Mol Sci. 2017;18(2).

37. Kim KH, Blasco-Morente G, Cuende N, Arias-Santiago S. Mesenchymal stromal cells: properties and role in management of cutaneous diseases. J Eur Acad Dermatol Venereol. 2017;31(3):414-423. 
International Medical Case Reports Journal

Dovepress

Publish your work in this journal

The International Medical Case Reports Journal is an international, peer-reviewed open-access journal publishing original case reports from all medical specialties. Previously unpublished medical posters are also accepted relating to any area of clinical or preclinical science. Submissions should not normally exceed 2,000 words or

4 published pages including figures, diagrams and references. The manuscript management system is completely online and includes a very quick and fair peer-review system, which is all easy to use. Visit http://www.dovepress.com/testimonials.php to read real quotes from published authors.

Submit your manuscript here: https://www.dovepress.com/international-medical-case-reports-journal-journal 